University of South Carolina

Scholar Commons

5-19-2007

\title{
Sea Surface pC02-SST Relationships Across a Cold-Core Cyclonic Eddy: Implications for Understanding Regional Variability and Air-Sea Gas Exchange
}

\author{
Feizhou Chen \\ Wei-Jun Cai \\ Claudia R. Benitez-Nelson \\ benitezn@mailbox.sc.edu \\ Yongchen Wang
}

Follow this and additional works at: https://scholarcommons.sc.edu/geol_facpub

Part of the Earth Sciences Commons

Publication Info
Published in Geophysical Research Letters, Volume 34, Issue 10, 2007.
Copyright 2007 by the American Geophysical Union.

This Article is brought to you by the Earth, Ocean and Environment, School of the at Scholar Commons. It has been accepted for inclusion in Faculty Publications by an authorized administrator of Scholar Commons. For more information, please contact digres@mailbox.sc.edu. 


\title{
Sea surface $p \mathrm{CO}_{2}$-SST relationships across a cold-core cyclonic eddy: Implications for understanding regional variability and air-sea gas exchange
}

\author{
Feizhou Chen, ${ }^{1}$ Wei-Jun Cai, ${ }^{1}$ Claudia Benitez-Nelson, ${ }^{2}$ and Yongchen Wang ${ }^{1}$ \\ Received 1 September 2006; revised 2 January 2007; accepted 23 March 2007; published 19 May 2007.
}

[1] This study is designed to improve the understanding of how biologically productive, cold-core cyclonic eddies affect sea surface $p \mathrm{CO}_{2}$ in the lee of the main Hawaiian Islands in the subtropical North Pacific Gyre. We identified three unique relationships between $p \mathrm{CO}_{2}$ and sea surface temperature (SST). A positive correlation between $p \mathrm{CO}_{2}$ and SST was observed in the waters surrounding the eddy suggesting surface $\mathrm{CO}_{2}$ is controlled primarily by thermodynamics. In contrast, a negative relationship was observed within the eddy core as a result of the upwelling of $\mathrm{CO}_{2}$-enriched subsurface waters. A third relationship existed throughout the rest of the eddy with reduced $p \mathrm{CO}_{2}$ suggesting a combination of biological uptake, physical upwelling and thermodynamic controls. In the absence of an eddy, this region is a $\mathrm{CO}_{2}$ sink, with the passage of the cold-core mesoscale eddy decreasing the magnitude of the sink by $\sim 17 \%$. However, if the general temperature correlation is used to predict $p \mathrm{CO}_{2}$ inside the cold eddy, it would overestimate the $\mathrm{CO}_{2}$ sink inside the eddy by $100 \%$. Citation: Chen, F., W.-J. Cai, C. Benitez-Nelson, and Y. Wang (2007), Sea surface $p \mathrm{CO}_{2}$-SST relationships across a cold-core cyclonic eddy: Implications for understanding regional variability and air-sea gas exchange, Geophys. Res. Lett., 34, L10603, doi:10.1029/2006GL028058.

\section{Introduction}

[2] Although a significant correlation exists between surface water $p \mathrm{CO}_{2}$ and sea surface temperature (SST) in the open ocean, sea surface $p \mathrm{CO}_{2}$-SST relationships are affected by a combination of factors, such as thermodynamics (e.g. temperature effects on $\mathrm{CO}_{2}$ dissociation and solubility), physical transport (the influence of lateral and vertical mixing of water with different concentrations of total inorganic carbon), and biological activity. Although these processes are all correlated both directly and indirectly with temperature, their relative effects may differ over geographical and temporal scales. Thus several different trends in $p \mathrm{CO}_{2}$-SST relationship coexist within the world oceans [e.g., Bates et al., 1998; Landrum et al., 1996; Lefèvre et al., 2002; Lefèvre and Taylor, 2002; Metzl et al., 1995; Olsen et al., 2004; Takahashi et al., 1997; Takahashi et al., 1993; Takahashi et

\footnotetext{
${ }^{1}$ Department of Marine Sciences, University of Georgia, Athens, Georgia, USA

${ }^{2}$ Department of Geological Sciences and Marine Science Program, University of South Carolina, Columbia, South Carolina, USA.
}

al., 2002; Tans et al., 1990; Wanninkhof and Feely, 1998]. As a result, seasonal and interannual variability of oceanic $\mathrm{CO}_{2}$ uptake is difficult to assess and there are large uncertainties in regional and global $\mathrm{CO}_{2}$ budgets [Takahashi et al., 1997; Takahashi et al., 2002; Tans et al., 1990].

[3] Large scale $p \mathrm{CO}_{2}$-SST relationships often miss episodic and mesoscale events. Therefore, the climatological distributions of sea surface $p \mathrm{CO}_{2}$ constructed by interpolating spatially and temporally limited oceanic $\mathrm{CO}_{2}$ observations may inaccurately represent the regional mean, particularly within the subtropical gyres [Mahadevan et al., 2004; Takahashi et al., 1997]. The net global flux of oceanic $\mathrm{CO}_{2}$ uptake is determined by a small difference between large in- and out-fluxes in the world oceans. Thus, it is sensitive to variability in these different regional estimates [Mahadevan et al., 2004]. As a result, the global $\mathrm{CO}_{2}$ air-sea fluxes obtained may involve significant errors [Takahashi et al., 1997]. Although such error could be ideally reduced by greatly increasing sampling density and frequency, this sampling strategy is difficult to implement due to limited resources. More mechanistic or process-oriented approaches are required to link $\mathrm{CO}_{2}$ concentration to other parameters. Since the subtropical gyres represent about $60 \%$ of the global ocean area [Quay and Stutsman, 2003], a more comprehensive understanding of sea surface $p \mathrm{CO}_{2}-\mathrm{SST}$ relationship and its controlling factors within the subtropical gyres is desired in order to more accurately estimate the global capacity of $\mathrm{CO}_{2}$ uptake.

[4] Recent studies suggested that mesoscale eddy-driven events may be a major process for supplying new nutrients to the upper ocean of oligotrophic subtropical gyres [Mahadevan and Archer, 2000; McGillicuddy et al., 1998; McGillicuddy and Robinson, 1997; Williams and Follows, 1998]. This upwelling of subsurface water likely results in a strong initial degassing of $\mathrm{CO}_{2}$ followed by a $\mathrm{CO}_{2}$ drawdown due to enhanced biological activity [Lefèvre et al., 2002]. Thus, during an eddy event, several competing effects that influence $p \mathrm{CO}_{2}$-SST relationships will be expected to coexist within subtropical oligotrophic waters that are generally influenced by thermodynamic rules alone [Lee et al., 1998]. The gas exchange of $\mathrm{CO}_{2}$ across eddies, particularly in oligotrophic waters, remains poorly understood. This study examines several $p \mathrm{CO}_{2}$-SST relationships and $\mathrm{CO}_{2}$ air-sea exchange in a cold-core cyclonic eddy, Cyclone Opal, that formed in the lee of the main Hawaiian Islands, an oligotrophic open ocean region in the subtropical North Pacific Gyre. This area serves as a natural laboratory with vigorous and continuous mesoscale eddies formed throughout the year, providing excellent opportunities for 
the study of the effects of eddies on surface water $\mathrm{CO}_{2}$ [Bidigare et al., 2003; Seki et al., 2001].

\section{Methods}

[5] Sea surface temperature (SST) imagery from the NOAA Geostationary Operational Environmental Satellite (GOES) showed that a first baroclinic cold-core cyclonic eddy, Cyclone Opal, outcropped at the surface by the end of February 2005 and persisted for $4 \sim 6$ weeks [BenitezNelson et al., 2007] (Figure 1a). Underway samples were collected from Cyclone Opal by the flow-through system on board of the R/V Wecoma during March 10th-28th, 2005, as part of the E-Flux study (Figure 1b). Underway $p \mathrm{CO}_{2}$ measurements were conducted along all transects and at process stations (including six IN-stations (at the center of the eddy) and three OUT-stations (outside the eddy)) by using a combined laminate-flow and shower-head equilibrator coupled to an infrared $\mathrm{CO}_{2}$ analyzer (Li-Cor 6252) system [Wang and Cai, 2004]. Atmospheric $\mathrm{CO}_{2}$ (in dry air) was measured periodically throughout the cruise, and averaged $\sim 369.4 \mu \mathrm{atm}( \pm 2 \mu \mathrm{atm})$ after a $100 \%$ humidity correction. Underway salinity and temperature data were available from R/V Wecoma during the cruise. Discrete water samples were collected with Niskin bottles for total alkalinity (TAlk) and dissolved inorganic carbon (DIC). TAlk was determined by Gran titration on board ship [Cai and Wang, 1998]. Water samples for DIC analysis were preserved with mercuric chloride and sent back to the laboratory for measurement [Cai and Wang, 1998; Wang and Cai, 2004].

\section{Results and Discussion}

\section{1. $p \mathrm{CO}_{2}$-SST Relationships}

[6] Two very different relationships were observed in surface waters between underway salinity, temperature, and $p \mathrm{CO}_{2}$ (Figures 2 and 3a). Sea surface $p \mathrm{CO}_{2}$ collected outside the eddy (OUT- $p \mathrm{CO}_{2}$; blue diamonds in Figures 2 and $3 a)$ is clearly distinguished from that collected at process stations within the eddy-core $\left(\mathrm{IN}-p \mathrm{CO}_{2}\right.$; red triangles in Figures 2 and 3a). Outside the eddy, a positive linear relationship exists between the natural logarithms of sea surface $p \mathrm{CO}_{2}$ and SST:

$$
\begin{aligned}
\ln p \mathrm{CO}_{2}= & 0.0408 * \mathrm{SST}+4.8288 \\
& \cdot\left(\mathrm{n}=1110, \mathrm{r}^{2}=0.84, \mathrm{p}<0.0001\right. \\
& \quad \text { root mean square error }(\mathrm{RMSE})=0.0074)
\end{aligned}
$$

[7] We categorize the data in this region as Group-I data (Figure 3a). The RMSE in the $p \mathrm{CO}_{2}$ prediction is within $3 \mu \mathrm{atm}$. The tight correlation suggests that temperature is a primary factor controlling sea surface $p \mathrm{CO}_{2}$ outside the eddy and the calculated slope, or temperature factor $\left(\partial \ln p \mathrm{CO}_{2} / \partial \mathrm{T}\right)$, is 0.0408 . This is essentially the same for isochemical seawater determined by Takahashi et al. [1993] for a much larger database and temperature range $\left(0.0423^{\circ} \mathrm{C}^{-1}\right.$ between $\left.2-28^{\circ} \mathrm{C}\right)$. This also suggests that other factors (e.g., DIC, TAlk, and salinity) are
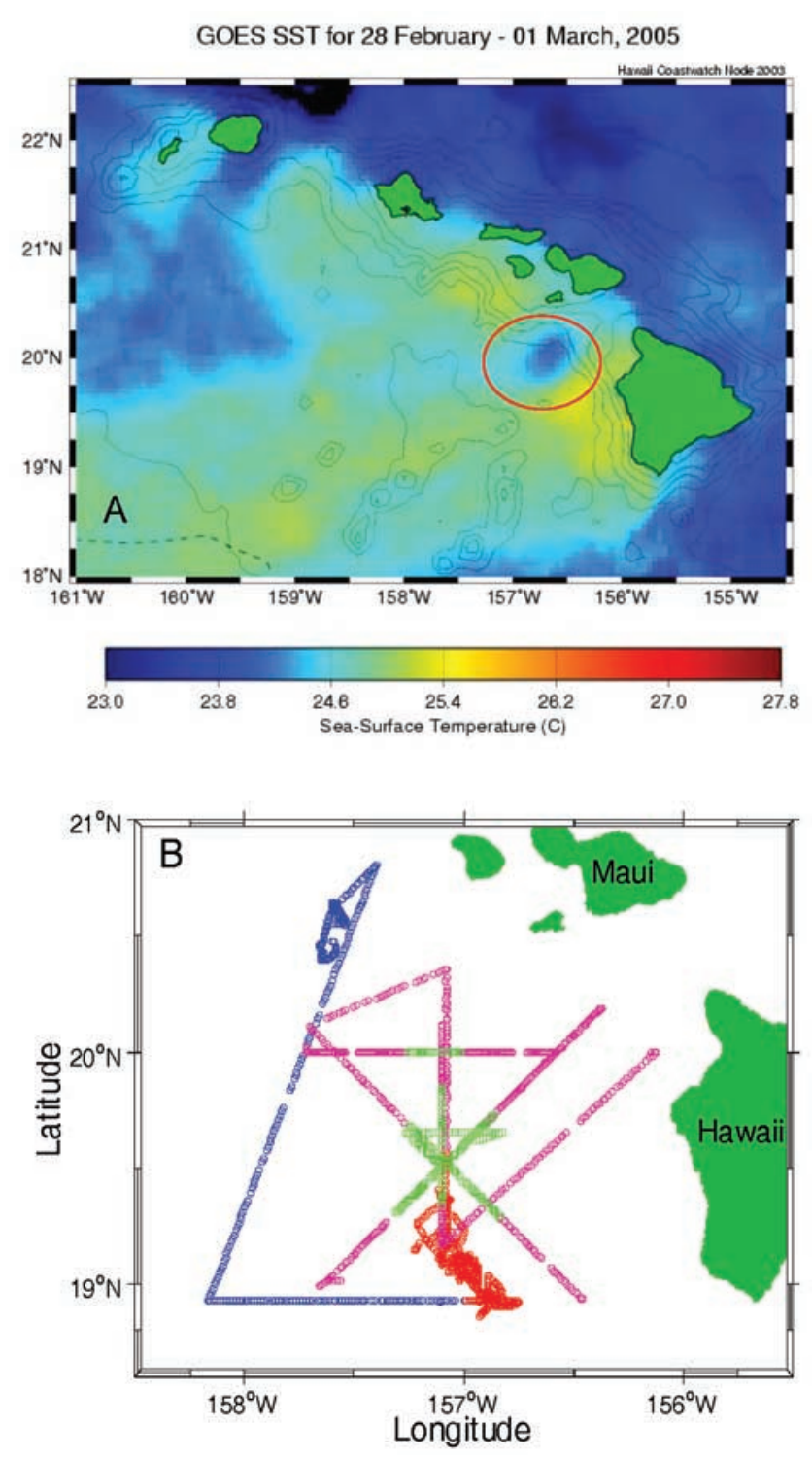

Figure 1. Remote sensing of SST in the lee of main Hawaiian Islands: (a) GOES SST image and (b) ship track during the E-Flux III, March, 2005, cruise. In Figure 1a, the cold core is marked with a red circle. In Figure $1 \mathrm{~b}$, the cruise track is divided into four groups. The initial sampling pattern consisted of several transects across the eddy. Temperature was used to distinguish Transects_In $\left(<24.5^{\circ} \mathrm{C}\right.$ and negative $p \mathrm{CO}_{2}$-SST, green) from Transects Out stations $\left(>24.5^{\circ} \mathrm{C}\right.$ and positive $p \mathrm{CO}_{2}$-SST, dark pink $\bar{k}$. After the completion of transects, IN-stations at the eddy core (as defined by temperature minima) were conducted (red). As the eddy was moving, the IN-stations did not match the center of the Transects_In. At the end of the cruise, the ship left Cyclone Opal, OUT-stations were conducted well outside the eddy flow field (blue).

generally constant at our reference sites (where most of the OUT- $p \mathrm{CO}_{2}$ was measured) [Takahashi et al., 1993; Takahashi et al., 2002]. Please note that this dataset does not include data collected during the transects (dark pink color in Figure 1b, see below). 
[8] The SST is much lower, and the salinity is much higher for the IN- $p \mathrm{CO}_{2}$ relative to the OUT- $p \mathrm{CO}_{2}$ (Figure 2). Surface waters with lower temperature and higher salinity, as well as higher $p \mathrm{CO}_{2}$ at the center of Cyclone $\mathrm{Opal}$, are consistent with the eddy outcropping at the surface. We categorize the negative relationship between $p \mathrm{CO}_{2}$ and SST as Group-II data (Figure 3a) and suggest that it is primarily controlled by physical transport-upwelling processes. Note, however that the relationship between $p \mathrm{CO}_{2}$ and SST within the eddy is not as straightforward as that observed outside Cyclone Opal. We believe that this is due to enhanced biological activity associated with the upwelling of new nutrients into the euphotic zone. These two processes act in opposition, where upwelling water enriched in DIC can be a potential $\mathrm{CO}_{2}$ source, and biological uptake, which consumes DIC, may be a sink due to the decrease of sea surface $p \mathrm{CO}_{2}$. Closer inspection of the IN- $p \mathrm{CO}_{2}$ data reveals a subset within the eddy core characterized by intermediate $p \mathrm{CO}_{2}$ values (between 344 and $350 \mu \mathrm{atm})$ and very low SST $\left(<24^{\circ} \mathrm{C}\right)$. Given the high rates of biological productivity observed [BenitezNelson et al., 2007], we believe that this subset reflects a combination of upwelling and biological uptake and is denoted as Group-III data (Figure 3a). Please note that Groups II and III are not clearly separated and the dividing line between them is somewhat arbitrary (Figure 3a).

[9] A better mechanistic understanding of how different processes may affect sea surface $p \mathrm{CO}_{2}$ can be assessed by separating the relative roles of (1) upwelling induced mixing, (2) the thermodynamic effect (warming), (3) gas exchange, and (4) biological uptake as shown in Figure $3 \mathrm{~b}$. The expected $p \mathrm{CO}_{2}$ resulting from the mixing of the original surface seawater and upwelled deep water is $355.4 \pm 10.0 \mu \mathrm{atm}, 16.8 \mu \mathrm{atm}$ higher than that of the original surface water (Figure $3 b$, also see auxiliary material). ${ }^{1}$ The mixed water mass was then warmed up from $22.94 \pm 0.28$ to $23.86 \pm 0.19^{\circ} \mathrm{C}$. Warming causes a $14 \mu \mathrm{atm}$ increase of $p \mathrm{CO}_{2} . \mathrm{CO}_{2}$ uptake from the atmosphere contributes another $2.6 \pm 1.9 \mu \mathrm{atm}$ increase in sea surface $p \mathrm{CO}_{2}$. Thus, the expected $p \mathrm{CO}_{2}$ is $372 \pm 10.9 \mu \mathrm{atm}$ (Figure $3 b$ ). The sea surface $p \mathrm{CO}_{2}$ values calculated from measured DIC and TAlk (average is $351.1 \pm 15.9 \mu \mathrm{atm}$ ) and measured underway (between 340 and $368 \mu \mathrm{atm}$ ) at the IN-stations are much lower. Thus, the contribution of biological uptake to $\mathrm{CO}_{2}$ drawdown is between 4-32 $\mu \mathrm{atm}$ atm and the average contribution is $21 \mu \mathrm{atm}$ (Figure 3b). The above analysis strongly supports our hypothesis that sea surface $p \mathrm{CO}_{2}$ within the eddy is a combined result of upwelling, warming, and biological uptake.

[10] Transect data across the eddy were subdivided by temperature into Transects_In $\left(<24.5^{\circ} \mathrm{C}\right.$ and a negative $p \mathrm{CO}_{2}$-SST relationship, green diamonds) and Transects_Out $\left(>24.5^{\circ} \mathrm{C}\right.$ and a positive $p \mathrm{CO}_{2}$-SST relationship, dark pink circles) (Figures 1b, 2, and 3a). The $p \mathrm{CO}_{2}$ data collected during the transects are consistent with our process stations results above. Transects In links the IN- $p \mathrm{CO}_{2}$ and OUT- $p \mathrm{CO}_{2}$ data and is a transition from upwelled high salinity, cold temperature waters within the eddy center to warmer surrounding waters outside the eddy.

${ }^{1}$ Auxiliary materials are available at ftp://ftp.agu.org/apend/gl/ $2006 \mathrm{~g} 1028058$.

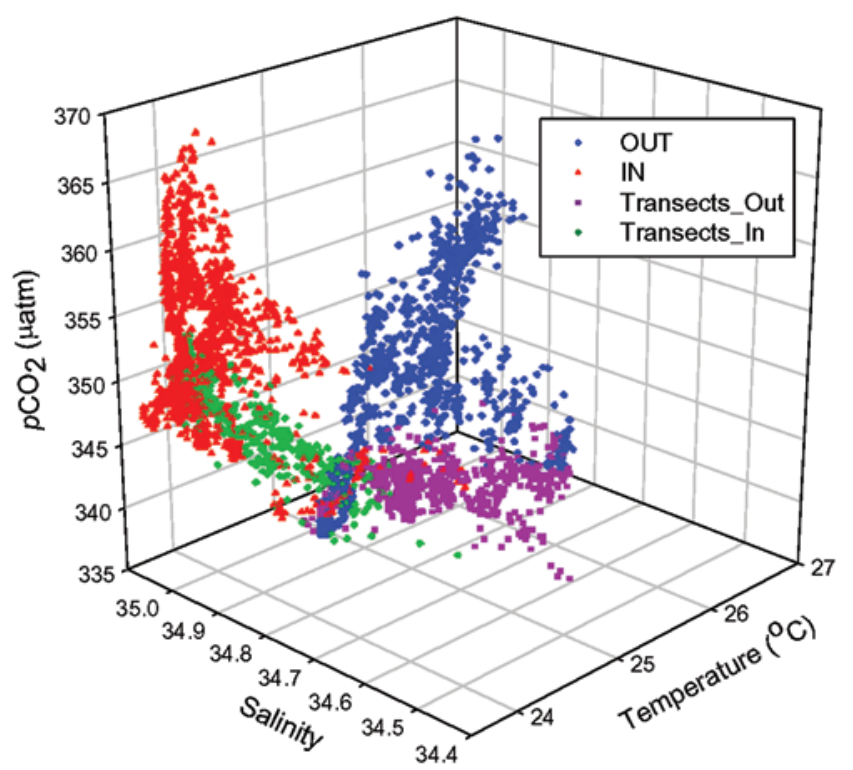

Figure 2. Relationship of sea surface $p \mathrm{CO}_{2}$ to SST and salinity. Data points with four different colors follow the ship track from Figure 1b: 'Transects_Out,' dark pink squares; 'Transects_In,' green diamonds; 'OUT,' blue diamonds; and ' $\mathrm{IN}$,' red triangles.

[11] The negative correlation between sea surface $p \mathrm{CO}_{2}$ and SST along Transects_In data is described by:

$$
\begin{aligned}
\ln p \mathrm{CO}_{2}= & -0.0257 * \mathrm{SST}+6.4691 \\
& \cdot\left(\mathrm{n}=376, \mathrm{r}^{2}=0.57, \mathrm{p}<0.0001, \mathrm{RMSE}=0.0052\right)
\end{aligned}
$$

Most of the IN- $p \mathrm{CO}_{2}$ data (Group-II data) from the process study stations in the eddy center falls along the upper part of the regression line for the Transects_In data in Figure 3a. Therefore, if these data are included in equation (2), the calculated slope would be more negative and comparable to the slope of $-0.049^{\circ} \mathrm{C}^{-1}$ (represented by a broken line in Figure 3a) reported in the upwelling zone of the Equatorial Pacific Ocean [Landrum et al., 1996]. Such a negative slope is also consistent with the observed $p \mathrm{CO}_{2}$-SST relationships $\left(-0.06^{\circ} \mathrm{C}^{-1}\right)$ for high-latitude surface waters due to winter mixing with water from below [Lee et al., 1998; Metzl et al., 1995; Takahashi et al., 1993].

[12] Note that Group-III data (the subset of IN- $p \mathrm{CO}_{2}$ data discussed above with intermediate $p \mathrm{CO}_{2}$ and very low SST) are similar to Transects_In data. Group-III data would merge into Transects_In $p \mathrm{CO}_{2}$ data if they are temperature-normalized (Figure 3c; see section 3.2.). Part of the Transects_In data are in the frontal zone (the confluence area of the cold eddy-core water and the surrounding warm oligotrophic water), where enhanced biological uptake relative to the surrounding waters is expected. Thus, Transects_In $p \mathrm{CO}_{2}$ data are consistent with our earlier interpretation that the relatively low $p \mathrm{CO}_{2}$ level in Group-III data is caused by biological uptake. 

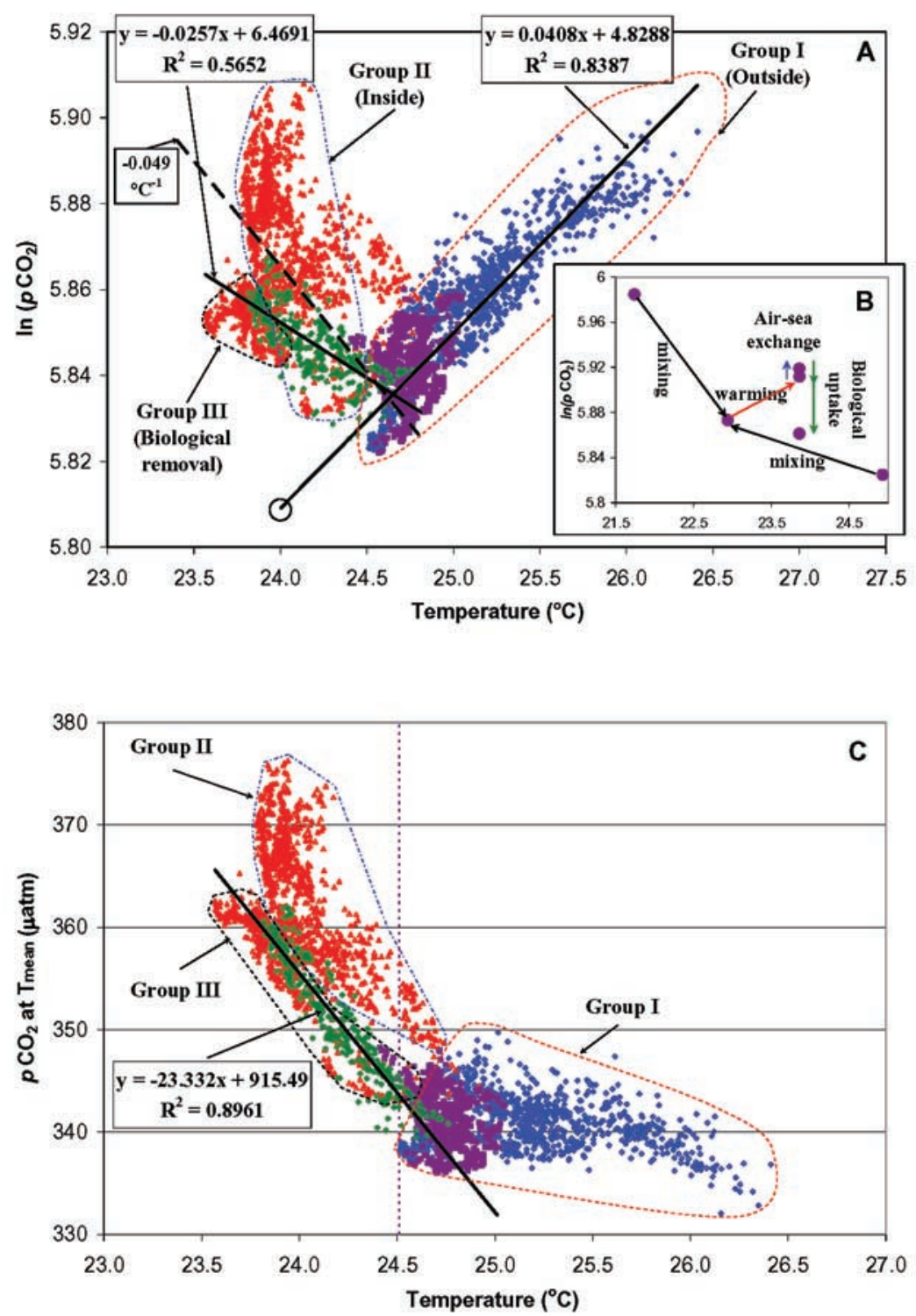

Figure 3. (a) Relationship between sea surface $p \mathrm{CO}_{2}$ (natural logarithms) and SST, (b) sea surface $p \mathrm{CO}_{2}$ of different water masses: diagram of different processes affecting $p \mathrm{CO}_{2}$, and (c) relationship between temperature-normalized $p \mathrm{CO}_{2}$ at temperature of $24.51^{\circ} \mathrm{C}$ and SST. Legend in Figures $3 \mathrm{a}$ and $3 \mathrm{c}$ is the same as that in Figure 2 and its meaning is described in Figure $1 \mathrm{~b}$. The $p \mathrm{CO}_{2}$ data in Figures 2 and $3 \mathrm{a}$ are the same. The large open circle in Figure $3 \mathrm{a}$ represents an average $p \mathrm{CO}_{2}$ value if the general positive correlation (Group-II line) is used to predict the value inside the eddy. In Figure $3 \mathrm{c}$, dashed line is at temperature $24.51^{\circ} \mathrm{C}$.

\subsection{Upwelling Versus Biological Uptake}

[13] It is interesting to point out that the $p \mathrm{CO}_{2}$ minimum occurs around a temperature of $24.4-24.6^{\circ} \mathrm{C}$ in the frontal zone (Figures 2 and 3a). As far as we know, such a $p \mathrm{CO}_{2}$ minimum within the frontal zone has not yet been reported in mesoscale or sub-mesoscale eddies, except that noted in the Sargasso Sea (i.e., surface $f \mathrm{CO}_{2}$ variability of $\sim 5-25 \mu \mathrm{atm}$ was observed across mesoscale cyclonic and anticyclonic eddies [Bates et al., 2000]). Similar patterns of a negative $p \mathrm{CO}_{2}$-SST relationship below a key temperature and a positive $p \mathrm{CO}_{2}$-SST relationship above that temperature has been reported elsewhere over larger spatial scales [e.g., Landrum et al., 1996; Takahashi et al., 1993].
Takahashi et al. [1993, 2002] observed a $p \mathrm{CO}_{2}$ minimum zone along the confluence of poleward-flowing warm subtropical waters and cold nutrient-rich subpolar waters and attributed it to a combination of warm water cooling and biological uptake in subpolar waters.

[14] Here, when cold nutrient-rich water from the eddycore outcrops to the surface and flows away from the center of the eddy, it contacts and mixes with the surrounding oligotrophic waters. The cooling of this oligotrophic water may result in the decrease of sea surface $p \mathrm{CO}_{2}$ outside the eddy. On the other hand, when the cold nutrient-rich eddycore water flows away from the eddy center, it also warms and potentially results in higher $p \mathrm{CO}_{2}$. But this warming 
effect on sea surface $p \mathrm{CO}_{2}$ (increase in $p \mathrm{CO}_{2}$ ) may be balanced and surpassed by the biological $\mathrm{CO}_{2}$ uptake at the confluence areas (frontal zone). Thus, the seawater may become increasingly undersaturated with respect to the atmosphere in spite of the warming. The observed $p \mathrm{CO}_{2}$ minimum in Figure 3a is likely a consequence of the above processes in this frontal zone, where primary production is no longer limited by nutrient deficits.

[15] In order to assess the effects of upwelling versus biological activity, we must first remove the temperature effect on in situ $p \mathrm{CO}_{2}$. Sea surface $p \mathrm{CO}_{2}$ data are normalized to a constant temperature of $24.51{ }^{\circ} \mathrm{C}$, the lowest SST value observed in the OUT- $p \mathrm{CO}_{2}$ data and the mean temperature of the overall data. We apply the method developed by Takahashi et al. [2002] to calculate the temperature-normalized $p \mathrm{CO}_{2}$ values:

$$
\left(p \mathrm{CO}_{2} \text { at } \mathrm{T}_{\text {mean }}\right)=\left(p \mathrm{CO}_{2}\right)_{\text {obs }} * \exp \left(0.0408 *\left(\mathrm{~T}_{\text {mean }}-\mathrm{T}_{\text {obs }}\right)\right)
$$

where $\mathrm{T}$ is the temperature in ${ }^{\circ} \mathrm{C}$, and the subscripts 'mean' and 'obs' indicate the chosen reference temperature and the in situ values, respectively. OUT- $p \mathrm{CO}_{2}$ data are assumed to be controlled by temperature only and are considered to be isochemical seawater. We also used the slope $\left(\partial \ln p \mathrm{CO}_{2} / \partial \mathrm{T}\right)$ of $0.0408^{\circ} \mathrm{C}^{-1}$ determined by our data rather than $0.0423^{\circ} \mathrm{C}^{-1}$ by Takahashi et al. [1993].

[16] The results are shown in Figure 3c. For $p \mathrm{CO}_{2}$ data outside the eddy (OUT- $p \mathrm{CO}_{2}$ and Transects_Out $\left.p \mathrm{CO}_{2}\right)$, the temperature-normalized values are nearly independent of the temperature, as expected for a water mass that follows thermodynamic rules [Takahashi et al., 1993]. For $p \mathrm{CO}_{2}$ data inside the eddy (IN- $p \mathrm{CO}_{2}$ and Transects_In $p \mathrm{CO}_{2}$ ), a negative relationship between temperature-normalized $p \mathrm{CO}_{2}$ and SST is observed when SST falls below $24.51^{\circ} \mathrm{C}$. For the large scale global ocean, Takahashi et al. [2002] attributed the temperature-normalized $p \mathrm{CO}_{2}$ drawdown via seasonal warming to biological uptake. In our case, the low temperature is, however, an indicator of upwelling. Thus, the temperature-normalized $p \mathrm{CO}_{2}$ values increase by $\sim 30 \mu \mathrm{atm}$ from a nearly constant reference value outside the eddy to the highest values at the eddy core due to the upwelling of high $p \mathrm{CO}_{2}$ deep water. Temperature-normalized $p \mathrm{CO}_{2}$ values in the eddy core that are higher than the outside waters are also supported by observed DIC data (see auxiliary material). DIC concentrations in surface waters at the eddy center are $\sim 15 \mu \mathrm{mol} \mathrm{kg}{ }^{-1}$ (normalized to a constant salinity of 35, data not shown here) higher than regional surface waters. Using a Revelle factor of 8.5 [Takahashi et al., 1993], the observed difference in total DIC can be translated into a $p \mathrm{CO}_{2}$ increase of nearly $30 \mu \mathrm{atm}$ inside the eddy (changes in alkalinity are small).

[17] There is a negative linear relationship between temperature-normalized $p \mathrm{CO}_{2}$ and SST for transects data within the eddy (Transects_In data) (Figure 3c)

$$
\begin{aligned}
\left(p \mathrm{CO}_{2} \text { at } \mathrm{T}_{\text {mean }}\right)= & -23.332 * \mathrm{SST}+915.49 \\
\cdot & \left(\mathrm{n}=376, \mathrm{r}^{2}=0.90, \mathrm{p}<0.0001,\right. \\
& \operatorname{RMSE}=1.84)
\end{aligned}
$$

Using this equation removes the thermodynamic effect of temperature (i.e., $\mathrm{CO}_{2}$ dissociation and solubility changes) on $p \mathrm{CO}_{2}$ and links $p \mathrm{CO}_{2}$ to upwelling. If we let $\Delta \mathrm{SST}=$ (SST - 24.51) and rewrite equation (4) as

$$
\begin{aligned}
\left(p \mathrm{CO}_{2} \text { at } \mathrm{T}_{\text {mean }}\right)= & -23.332 * \Delta \mathrm{SST}+343.62 \\
& \cdot\left(\mathrm{n}=376, \mathrm{r}^{2}=0.90, \mathrm{p}<0.0001,\right. \\
& \mathrm{RMSE}=1.84)
\end{aligned}
$$

then a general prediction of $p \mathrm{CO}_{2}$ in eddy-influenced areas can be developed after further adjustment to parameters such as the slope and $\triangle \mathrm{SST}$. For example, here, a temperature of $24.51^{\circ} \mathrm{C}$ is used as the boundary condition to separate surface water inside the eddy from surrounding warmer subtropical surface waters. This boundary temperature and the slope in equation (5) could be seasonally and geographically different. Therefore, with further research, equation (5) combined with equation (3), may be useful for satellite assessments of sea surface $p \mathrm{CO}_{2}$ distributions and air-sea fluxes of $\mathrm{CO}_{2}$ in the future.

\subsection{Air-Sea Fluxes of $\mathrm{CO}_{2}$}

[18] The average wind speed from the meteorological data on NDBC buoy 51003 (location: $19.16^{\circ} \mathrm{N}$ and $160.74^{\circ} \mathrm{W}$ ) was $6.6 \mathrm{~m} \mathrm{~s}^{-1}$ in March 2005. $\mathrm{CO}_{2}$ fluxes were calculated from this wind speed (adjusted to $10 \mathrm{~m}$ height), the $\Delta p \mathrm{CO}_{2}$ (difference in average $p \mathrm{CO}_{2}$ between surface water and atmosphere) and Wanninkhof's equation [Wanninkhof, 1992]. The overall average sea-to-air $\mathrm{CO}_{2}$ fluxes in the entire region, within the eddy core (In) and outside the eddy (Out) are estimated to be $-2.6( \pm 1.8)$, $-2.4( \pm 1.8)$, and $-2.9( \pm 1.8) \mathrm{mmol} \mathrm{C} \mathrm{m}{ }^{-2} \mathrm{day}^{-1}$, respectively. In all cases, estimated sea-air fluxes are negative, and hence this area is a regional $\mathrm{CO}_{2}$ sink throughout the cruise period as reported previously [Dore et al., 2003; Landrum et al., 1996]. Interestingly, however, Cyclone Opal was less of a sink (i.e., a 17\% reduction inside the eddy vs. the outside area). Furthermore, if we apply the general $p \mathrm{CO}_{2}$-SST correlation outside the eddy (i.e., equation (1)) to the region inside the eddy, the predicted sea surface $p \mathrm{CO}_{2}$ value would be about $333 \mu \mathrm{atm}$ atm at $24^{\circ} \mathrm{C}$ (the average value is indicated with a large open circle along the Group-I line in Figure 3a). The predicted average sea-to-air $\mathrm{CO}_{2}$ flux would be about $-4.8 \mathrm{mmol} \mathrm{C} \mathrm{m}^{-2} \mathrm{day}^{-1}$, which represents a $100 \%$ overestimation of the real $\mathrm{CO}_{2}$ uptake inside the eddy. Therefore, although cyclonic eddies are highly productive, their impact on the carbon cycling and sea surface $\mathrm{CO}_{2}$ exchange with the atmosphere are complex and needs to be closely examined in light of low observed particle export rates [Benitez-Nelson et al., 2007]. With an estimated annual average of 9 cyclonic eddies driven by trade winds in the lee of the main Hawaiian Islands [Lumpkin, 1998], the influence of eddies on $\mathrm{CO}_{2}$ air-sea exchange deserves much greater attention and further research.

\section{Concluding Remarks}

[19] Our findings help improve the accuracy of global climatological $p \mathrm{CO}_{2}$ distributions by assessing the role of mesoscale eddies [Robinson, 1983]. Our estimates also suggest that although cyclonic eddies substantially enhance 
primary production, they do not necessarily enhance $\mathrm{CO}_{2}$ air-sea exchange in a subtropical ocean. We conclude that this is mostly due to the balance of two competing mechanisms: vertical upwelling and biological uptake. However, if we neglect the $\mathrm{CO}_{2}$ variability due to mesoscale eddies and apply a general sea surface $p \mathrm{CO}_{2}$-SST equation from oligotrophic waters to interpolate sea surface $p \mathrm{CO}_{2}$ inside the eddy, significant bias in the estimation of regional $\mathrm{CO}_{2}$ air-sea flux is expected. This is consistent with results from the Sargasso Sea near Bermuda where the variability of $\mathrm{CO}_{2}$ fluxes was reduced from $30 \%$ to within $10 \%$ when more frequent $p \mathrm{CO}_{2}$ measurements were implemented [Bates et al., 1998]. Thus we conclude that other types of eddies in various stages of their life cycle need to be evaluated for their $p \mathrm{CO}_{2}-\mathrm{SST}$ relationships and $\mathrm{CO}_{2}$ air-sea exchange in order to fully understand their impact on global $\mathrm{CO}_{2}$ exchange processes.

[20] Acknowledgments. We are grateful to C. L. Leonard and the NOAA Ocean Watch Central Pacific for the satellite SST image. We thank B. Bidigare, T. Dickey, W. Black, F. Nencioli, and V. Kuwahara for their help during the cruise. We also thank the crew of the Wecoma for logistical support. This work was supported by the National Science Foundation (OCE-0425153 to W.-J. Cai and OCE-0241645 to C. Benitez-Nelson).

\section{References}

Bates, N. R., T. Takahashi, D. W. Chipman, and A. H. Knap (1998), Variability of $\mathrm{pCO}_{2}$ on diel to seasonal timescales in the Sargasso Sea near Bermuda, J. Geophys. Res., 103, 15,567-15,585.

Bates, N. R., L. Merlivat, L. Beaumont, and A. C. Pequignet (2000), Intercomparison of shipboard and moored CARIOCA buoy seawater $\mathrm{fCO}_{2}$ measurements in the Sargasso Sea, Mar. Chem., 72, 239-255.

Benitez-Nelson, C. R., et al. (2007), Mesoscale eddies drive increased silica export in the subtropical North Pacific Ocean, Science, in press.

Bidigare, R. R., C. Benitez-Nelson, C. L. Leonard, P. D. Quay, M. L. Parsons, D. G. Foley, and M. P. Seki (2003), Influence of a cyclonic eddy on microheterotroph biomass and carbon export in the lee of Hawaii, Geophys. Res. Lett., 30(6), 1318, doi:10.1029/2002GL016393.

Cai, W.-J., and Y. Wang (1998), The chemistry, fluxes and sources of carbon dioxide in the estuarine waters of the Satilla and Altamaha Rivers, Georgia, Limnol. Oceanogr., 43, 657-668.

Dore, J. E., R. Lukas, D. W. Sadler, and D. M. Karl (2003), Climate-driven changes to the atmospheric $\mathrm{CO}_{2}$ sink in the subtropical North Pacific Ocean, Nature, 424, 754-757.

Landrum, L. L., R. H. Gammon, R. A. Feely, P. P. Murphy, K. C. Kelly, C. E. Cosca, and R. F. Weiss (1996), North Pacific Ocean $\mathrm{CO}_{2}$ disequilibrium for spring through summer, 1985-1989, J. Geophys. Res., 101, 28,539-28,555.

Lee, K., R. Wanninkhof, T. Takahashi, S. C. Doney, and R. A. Feely (1998), Low interannual variability in recent oceanic uptake of atmospheric carbon dioxide, Nature, 396, 155-159.

Lefèvre, N., and A. Taylor (2002), Estimating $\mathrm{pCO}_{2}$ from sea surface temperatures in the Atlantic gyres, Deep Sea Res., Part I, 49, $539-554$.

Lefèvre, N., J. Aiken, J. Rutllant, G. Daneri, S. Lavender, and T. Smyth (2002), Observations of $\mathrm{pCO}_{2}$ in the coastal upwelling off Chile: Spatial and temporal extrapolation using satellite data, J. Geophys. Res., 107(C6), 3055, doi:10.1029/2000JC000395.

Lumpkin, C. F. (1998), Eddies and currents of the Hawaiian Islands, Ph.D. dissertation, 281 pp., Univ. of Hawaii, Manoa.

Mahadevan, A., and D. Archer (2000), Modeling the impact of fronts and mesoscale circulation on the nutrient supply and biogeochemistry of the upper ocean, J. Geophys. Res., 105, 1209-1225.

Mahadevan, A., M. Lévy, and L. Mémery (2004), Mesoscale variability of sea surface $\mathrm{pCO}_{2}$ : What does it respond to?, Global Biogeochem. Cycles, 18, GB1017, doi:10.1029/2003GB002102.

McGillicuddy, D. J., Jr., and A. R. Robinson (1997), Eddy-induced nutrient supply and new production in the Sargasso Sea, Deep Sea Res., Part I, 44, 1427-1450.

McGillicuddy, D. J., Jr., A. R. Robinson, D. A. Siegel, H. W. Jannasch, R. Johnson, T. D. Dickey, J. McNeil, A. F. Michaels, and A. H. Knap (1998), Influence of mesoscale eddies on new production in the Sargasso Sea, Nature, 394, 263-266.

Metzl, N., A. Poisson, F. Louanchi, C. Brunet, B. Schauer, and B. Bres (1995), Spatio-temporal distributions of air-sea fluxes of $\mathrm{CO}_{2}$ in the Indian and Antarctic Oceans: A first step, Tellus, Ser. B, 47, 56-69.

Olsen, A., J. A. Trinanes, and R. Wanninkhof (2004), Sea-air flux of $\mathrm{CO}_{2}$ in the Caribbean Sea estimated using in situ and remote sensing data, Remote Sens. Environ., 89, 309-325.

Quay, P., and J. Stutsman (2003), Surface layer carbon budget for the subtropical N. Pacific: $\delta^{13} \mathrm{C}$ constraints at station ALOHA, Deep Sea Res., Part I, 50, 1045-1061.

Robinson, A. R. (1983), Overview of eddy science, in Eddies in Marine Science, edited by A. R. Robinson, pp. 3-15, Springer, Berlin.

Seki, M. P., J. J. Polovina, R. E. Brainard, R. R. Bidigare, C. L. Leonard, and D. G. Foley (2001), Biological enhancement at cyclonic eddies tracked with GOES thermal imagery in Hawaiian waters, Geophys. Res. Lett., 28, 1583-1586.

Takahashi, T., J. Olafsson, J. G. Goddard, D. W. Chipman, and S. C. Sutherland (1993), Seasonal-variation of $\mathrm{CO}_{2}$ and nutrients in the highlatitude surface oceans: A comparative study, Global Biogeochem. Cycles, 7, 843-878.

Takahashi, T., R. A. Feely, R. F. Weiss, R. H. Wanninkhof, D. W. Chipman, S. C. Sutherland, and T. T. Takahashi (1997), Global air-sea flux of $\mathrm{CO}_{2}$ : An estimate based on measurements of sea-air $\mathrm{pCO}_{2}$ difference, Proc. Natl. Acad. Sci. U. S. A., 94, 8292-8299.

Takahashi, T., et al. (2002), Global sea-air $\mathrm{CO}_{2}$ flux based on climatological surface ocean $\mathrm{pCO}_{2}$, and seasonal biological and temperature effects, Deep Sea Res., Part II, 49, 1601-1622.

Tans, P. P., I. Y. Fung, and T. Takahashi (1990), Observational constraints on the global atmospheric $\mathrm{CO}_{2}$ budget, Science, 247, 1431-1438.

Wang, Z. H. A., and W. J. Cai (2004), Carbon dioxide degassing and inorganic carbon export from a marsh-dominated estuary (the Duplin River): A marsh $\mathrm{CO}_{2}$ pump, Limnol. Oceanogr., 49, 341-354.

Wanninkhof, R. (1992), Relationship between wind-speed and gasexchange over the ocean, J. Geophys. Res., 97, 7373-7382.

Wanninkhof, R., and R. A. Feely (1998), $\mathrm{fCO}_{2}$ dynamics in the Atlantic, South Pacific and South Indian oceans, Mar. Chem., 60, 15-31.

Williams, R. G., and M. J. Follows (1998), Eddies make ocean deserts bloom, Nature, 394, 228-229.

C. Benitez-Nelson, Department of Geological Sciences and Marine Science Program, University of South Carolina, Columbia, SC 29208, USA.

W.-J. Cai (corresponding author), F. Chen, and Y. Wang, Department of Marine Sciences, University of Georgia, Athens, GA 30602, USA. (wcai@uga.edu) 